\title{
Circular economy as a strategic option to promote sustainable economic growth and effective human development
}

\author{
Armenia Androniceanu \\ Department of Administration and Public Management, \\ Bucharest University of Economic Studies, \\ Romania; \\ Research Department, University of Social Sciences, Lodz, \\ Poland \\ armenia.androniceanu@man.ase.ro \\ ORCID 0000-0001-7307-5597
}

\section{Jani Kinnunen}

Department of Information Systems,

Abo Akademi University,

Finland

jani.kinnunen@abo.fi

ORCID 0000-0002-0154-6617

\section{Irina Georgescu}

Department of Economic Informatics and Cybernetics,

Bucharest University of Economic Studies,

Romania

irina.georgescu@csie.ase.ro

ORCID 0000-0002-8536-5636

Abstract. Promotion and implementation of sustainable production and consumption practices have become a priority to obtain social, economic, and environmental benefits. Circular economy is based on an integrative approach which requires the analysis of all the relevant factors that may determine changes in the classical linear model of economic growth. From this perspective, we should talk not only about some sector of activity as a net contributor to the circular economy but of several sectors. Our research aim was to identify and analyze the contributors to circular economy and its evolution within the EU member states from three broader perspectives: sustainable development, environment, and economic growth. Another objective was to reduce the data dimensionality by applying principal component analysis (PCA). Databases of the Eurostat and the World Bank were utilized to select 13 key indicators. The PCA research method was applied to $25 \mathrm{EU}$ member states in the year 2018. Three factors were found to explain $70.06 \%$ of the total variation in data, the main components were identified, and a circular economy index was constructed for comparative purposes. The results suggest that circular economy is a strategic option

Received: May, 2020 1st Revision: December, 2020

Accepted:

March, 2021

$$
\text { DOI: }
$$


exercisable to create competitive advantage and promote sustainable economic growth.

Keywords: circular economy, economic growth, human development, principal component analysis.

JEL Classification: C38, F43, O15

\section{INTRODUCTION}

The world is facing huge challenges. Deep and rapid economic, climate and technological changes are taking place, all requiring changes in the economic model of development. It becomes necessary to gradually give up the linear economy. This model has created an economy that largely depends on the use of energy and other limited resources to produce and deliver products and services, which leads to the degradation of the natural environment (Ionescu, 2020; Hodgkins, 2020). Excessive resource consumption and accelerated environmental degradation in the recent decades have led EU countries and the institutions in Brussels to replace the linear economic model with that of the circular economy. The model of linear economy must be changed as soon as possible with that of circular economy. The widespread adoption of circular economy requires coordinated efforts to redesign all production schemes and business models in a circular perspective. This means that it is necessary to harmonize the long-term development needs of humanity and to optimize resource consumption so that both population and economic agents waste as little as possible and reuse as much as possible (Walker et al., 2020). Improving the use of resources must not affect their rate of natural recovery, in sufficient quantities for future generations.

Circular economy involves the efficiency of resources to produce more economic value with the same or fewer resources and environmental protection by neutralizing or capitalizing on waste from the economic and social environment (Haseeb et al., 2021). Therefore, circular economy consists in designing a system that aims to make more efficient use of resources and reduce the impact on the environment, while not neglecting the well-being of people. In short, when we think of a product, we must consider its entire life cycle, from the design phase to the time when it can no longer be used. According to the linear model, at the end of a life cycle, products are usually thrown away or stored. The circular economy proposes a new approach in three steps: reduction-reuse-recycling. As a result, the overall health of the planet is restored (Shpak et al., 2020).

It is well known that companies in many economic sectors in some EU countries, especially in the UK, the Netherlands, Denmark, Germany and some Nordic countries, have already taken important steps towards adopting the circular economy model, and this has cost them. What is important to note here is that companies that have made progress in implementing circular economy models have already reached maturity and are doing so within the economic systems in which relations between companies and consumers, those of industrial symbiosis and those related to promoting sustainability in the value chain are already mature, involving only minor adjustments. Transition to a circular economy is necessary because it can bring real benefits such as reducing pressure on the environment, improving the security of raw materials supply, increasing competitiveness, stimulating innovation, stimulating growth, job creation (580,000 new jobs in the EU alone). Consumers will also benefit from more sustainable and innovative products which will increase their quality of life and help them save money in the long run.

In our research, we aimed to know and analyze the impact that the transition to circular economy has had on economic development of the EU countries. Our research includes all the EU states and is focused on three dimensions: circular economy itself, economic growth and the environment. The research was 
conducted based on specific indicators using time series for each dimension (Moraga et al., 2019). Through a specific correlation and causal analysis, we aim to discover how states' economies have changed over time, what was the impact but also the essential correlations in the process of change, as a result of the transition from linear to circular economic model, under the aspect of economic growth, sustainable development, and environment (Connolly-Barker et al., 2020; Morgan, 2020).

Our research stems from the following key question: Is circular economy a viable strategic option for sustainable economic development in the EU countries? The results of our research suggest that transition to circular economy has a significant impact on the sustainable economic and human development of the EU countries. The correlative approach we have applied here proves that circular economy in relation with economic growth and human development is a necessary, feasible and sustainable strategic option for the Member States' economies.

\section{LITERATURE REVIEW}

The circular economy is a generic term used for an industrial economy that is created to be restorative and in which the material cycle is of two kinds: the biological cycle, where processes act so that components re-enter the environment without negative effects, and the second cycle is the technical/industrial one, in which the components are used efficiently to produce other goods. According to the literature, the concept of the circular economy has been studied by several specialists with different visions but based on the same principles. There is no precise date when a certain author explained this concept, but some applications were developed in the late '70s. The first belongs to Kenneth E. Boulding (1966). In his paper entitled "The Economics of the Coming Spaceship Earth" he presented and explained the idea of circular material flow as an economic model. The notion of the circular economy appears to be used for the first time in an economic model, by Pearce and Turner (1990) who finds that the traditional or linear economic model lacks the idea of recycling, which affects the environment-economy relationship.

One of the most well-known definitions of the circular economy is the one formulated within the Ellen MacArthur Foundation: "an industrial system that is restorative or regenerative by intention and design" (2013, p.7). As part of its educational mission, the specialists within the foundation aimed to unite the different complementary schools of thought and to create a unitary framework, thus increasing the interest in the concept. According to Steffen et al. (2015), the circular economy is the fundamental alternative to the linear economic model. The authors emphasize that the linear model is not sustainable because it is based on the premise that natural resources are available without restrictions and are easily accessible. This idea is no longer valid today, when resources are declining and environmental pollution is increasing, thus endangering life on the planet (Nelson, Neguriță, 2020).

In a study conducted in the United States, Esposito et al. (2015) present the main benefits that the circular economy can bring. One of the benefits would be to have economic growth based on the use of materials already in the system and the lower use of natural resources. One of the precise definitions, provided by Zielińska (2019), is explaining that the key goal of the circular economy is to manufacture and use products in the most efficient way due to managing the waste in an economically and environmentally appropriate manner. A study by Banaité (2016) showed that the circular economy has emerged as a solution to the problems facing the linear economy: limited production of declining access to natural resources, an increased level of pollution and a rate increased energy consumption. One can therefore state that main advantages of the circular economy model include: 1) optimal waste disposal; 2) innovative and resource efficient methods of production and consumption; 3) energy savings due to a closed production cycle; 4) reducing the negative impact on the environment; 5) protecting the economy from resource scarcity (Shpak et al., 2021). 
The circular economy in China has experienced a different approach, on a national scale and of unprecedented magnitude. In the Asian literature, there are empirical studies on measuring the circular economy, case studies and complex analyzes that show that the application of the circular economy model in the Chinese economy is one of the factors that generated the economic success of this country later (Geng, et al., 2012; 2013). Most studies clearly show that China's economic success has been due to the circular economy, which has developed nationally in this country, effectively contributing to sustainable economic development (Geng, et al., 2013). Other authors explain the circular economy by the fact that the value of products, materials and resources is kept as much as possible in the economy and waste generation is kept to a minimum (Nekmahmud et al., 2020).

The circular economy has preoccupied European states for decades, as the problems posed by limited resources, climate change due to environmental pollution with a variety of industrial waste, slowing economic growth and others have become increasingly visible. The European Union produces more than 2.5 billion tonnes of waste annually. In recent years, the European Union has been updating its waste management legislation to promote the transition to a more sustainable model known as the circular economy. This major structural change in economic systems is needed (Kosach et al., 2020).

It is estimated that 88 million tons of food waste are generated annually in the EU, about 173 kilograms per capita. In farms, in processing and production, in shops, restaurants and at home food is lost and wasted along the entire food chain. In the first place in the generation of food waste are households. It is necessary for citizens to better understand the notions of food safety, food waste and its causes. It is necessary to replace the classical, linear economy. The consequences of this type of economy include an increase in the consumption of natural resources, most of which are limited, an increase in environmental pollution, as a result of the waste released and reduced economic efficiency (Gavurova et al., 2020).

On the other hand, the circular economy reduces the consumption of natural resources, reduces carbon emissions and optimizes costs regardless of their nature, develops opportunities in the business environment and creates jobs. Recycling is essential in this circular process because it ensures the link between the initial and final point of the process, by transforming waste materials into raw materials for other production processes. The low rate of plastic recycling in the EU leads to high losses for both the economy and the environment. It is estimated that $95 \%$ of the value of the plastic packaging material is lost after the short cycle of the first use. Every year, the production and incineration of plastics emit around 400 million tonnes of $\mathrm{CO} 2$ globally, some of which can be avoided by better recycling. Plastic production has grown exponentially worldwide in just a few decades, from 1.5 million tonnes in 1950 to almost 400 million tonnes in 2020 .

Although, at first glance, the concept of the circular economy seems to be motivated by environmental reasons, most reports and research underpinning the legislative package approved by the EU in 2015 highlight a wider range of motivations and much deeper implications for economic developments. medium and long term.

The new EU regulatory framework sets the target of collecting $90 \%$ of water bottles (for example, through landfill systems) by 2029. Moreover, it aims to bring the percentage of recycled plastic bottles to $25 \%$. by 2025 and $30 \%$ by 2030 of all recycled plastic products. A recent EU waste proposal provides for long-term recycling targets for packaging waste, measures to limit their disposal, but also incentives for the Member States to use new economic instruments at the national level. The same proposal promotes cooperation between industries through a simplified legislative framework to transform the waste generated by one industry into secondary materials used by another.

In this European economic context, the circular economy represents a new, emerging perspective on sustainable development. Some studies analyze the transition to the circular economy in the EU (Mazzoni, 2020; Stankevičius et al., 2020; Nikanorova \& Stankevičiené, 2020). They show that the European Union 
has heterogeneous results in terms of the transition to the circular economy. Italy and Spain demonstrate a medium-high level of development, while Romania is at the bottom of the ranking. To measure performance over time, the Circular Economy Scoreboard analysis model was used for 5 years. Romania has seen a significant improvement in the last five years, Spain has made moderate progress, while Italy has had a slower evolution in the transition to a circular model. The assessment of the "level of circularity" of the 27 EU countries and the United Kingdom was completed by a survey, in which 300 European business leaders were asked about the need for circular measures in companies. Almost $95 \%$ of respondents consider the circular economy to be a strategic choice for their company, which helps to gain a competitive advantage in terms of diversification, expanding market share and reducing costs (Geissdoerfer et al., 2017).

According to the research results most European countries are not prepared to face the challenges of the circular economy. Uncertainty about value creation (43.6\% of responses) and lack of skills $(35.9 \%)$ are the two most common responses to obstacles to the development of the circular economy in Europe. Given the crucial role of the circular economy in current political discourse at both European and national level, the study was complemented by a quantitative assessment of the socio-economic and environmental benefits of the circular economy.

Many European countries do not yet have a national strategy for the circular economy as a key factor. Therefore, assessing the state of the circular economy in relation to economic growth and human development in Europe and identifying their impact on sustainable economic development in Europe, causality and environmental effects are research objectives that we have pursued in this process.

Our study covers EU countries. We have chosen Principal Component Analysis to reflect the transformations in the European system and reveal their causality, impact and effects. The research methodology is presented in the next section of our paper. The results are representative of Europe and show that there is a real need and huge potential for the Member States to grow and be competitive by applying the circular economy model.

Economic growth is seen as an expression of the chances for a better life and is therefore a major objective of macroeconomic policy. Economic growth is interpreted as a positive, upward trend in macroeconomic performance. Economic growth consists of the quantitative increase of the activities and their results on the whole national economy in close connection with the factors that contribute to this increase. Economic growth is conditioned by existing potential resources and how they are used.

All countries have these factors, to a greater or lesser extent, but there is no single formula to use them to ensure economic growth. An important influence on economic growth has indirect factors, with immediate action: the size of aggregate demand, respectively, the absorption capacity of the internal market; the efficiency of the banking financial system; savings rate and investment rate; the international environment; labor and capital migration; state budgetary and fiscal policy. Among factors of economic growth intellectual potential has increasing influence on social and economic development (Androniceanu et al., 2020; Bilan et al., 2020; Kinnunen et al., 2019; Mendy \& Widodo, 2018). Several authors consider that small and medium-sized enterprises are the main contributor to the economic growth (Krisnaresanti et al., 2020; Dvorský et al., 2020; Bilas et al., 2020). Economic growth is a key term in economic science that designates the upward dynamics of the real gross national product per capita as an expression of the quantitative correlations between the factors that influence its size and the economic and social environment in which it takes place.

Theories and models of economic growth highlight different ways in which the present activity influences the future and identifies the sources that can lead to continuous growth. The classical models of A. Smith and D. Ricardo described the evolution of the economy in terms of limited land and growing population. The Keynesian model of growth is a macroeconomic model, according to which national income increases in response to increasing aggregate demand. The Harrod-Domar model highlights three 
major problems: the possibility of sustained growth; the probability of a sustained increase in full employment conditions and the existence or not of the stability of the guaranteed growth rate.

The neoclassical model of growth explains how capital accumulation and technological change influence the economy. The new theory of economic growth states that an accumulation of capital must be associated, as a rule, with an accumulation of knowledge. The new theory has two basic models: 1) the "learning by doing" model and 2) the "innovation" model.

The third component of our analysis is human development. Development must lead to an improvement in people's quality of life and to their ability to shape their own future (Mura et al., 2019). The concept of human development is linked in a compatible and complementary way to human rights rights (e.g. Habanik et al., 2020; Khan et al., 2020; Kinnunen et al., 2019; Bagirova \& Notman, 2020). If human development aims to expand the possibilities and freedoms enjoyed by members of a community, then human rights are an approach to improving social structures that facilitate or ensure these possibilities and freedoms. From the perspective of human development, people's choices can be extended to three critical areas: life expectancy, education and access to the economic resources needed for a decent living (Prívara \& Kiner, 2020). In this context, Rozsa et al. (2020) said, that human potential is the most important resource of economic growth for each company. Belas et al. (2020) presented the results of case study in which more than $80 \%$ the Czech and $85 \%$ Slovak's entrepreneurs consider human capital in the company as one of the most important resources.

Human development is both a process and a final result (Vlacseková \& Mura, 2017). Other areas of choice, to which people also attach high value, are participating in social life, security, responsible governance and sustainability. From the point of view of human development, all this is necessary to ensure productivity and creativity, self-respect and a sense of belonging to a community. Ultimately, human development is the development of people, for people and through people.

The essential difference between the concept of economic growth and human development is that the former focuses exclusively on expanding a single possibility - that of obtaining income, while the latter involves consolidating all possibilities - whether economic, social, cultural or political.

\section{METHODOLOGY}

Principal Component Analysis (PCA) is a statistical procedure useful to extract information from a multidimensional space by projecting it to a lower dimensional space (Joliffe, 2002). The components that have more data variation are retained, while the less important components with fewer variation are not preserved. The principal components (PCs) are eigenvectors of the covariance matrix. The first PC maximizes the variance of the data.

We selected 13 variables from different databases: Eurostat, World Bank, European Environmental Agency, available for 2017 and 2018: Recycling rate of municipal waste (\% of total waste generation) (V1), Resource productivity and domestic material consumption (V2), Generation of municipal waste per capita (kg per capita) (V3), GDP growth (annual \%) (V4), Environmental tax revenues (\% of GDP) (V5), Research and development expenditure (\% of GDP) (V6), Annual change renewables (\%) (V7), Greenhouse gas emissions (V8), Human development index (HDI) (V9), Pollution Index (V10), Total natural resources rents (\% of GDP) (V11), Adjusted net savings including emissions damage (V12) and National expenditure on environmental protection (V13).

\section{EMPIRICAL RESULTS AND DISCUSSION}

Before applying PCA, we compute the correlation matrix seen in Figure 1. From the correlation matrix, one can see a strong positive correlation of 0.72 between Recycling rate of municipal waste (V1) and HDI 
(V9). GDP growth (V4) is included in human development, the latter also containing the living standard. Economic and human development are related in the sense that they both measure social welfare. The difference between them is that human development measures both the social and economic factors as components of well-being.

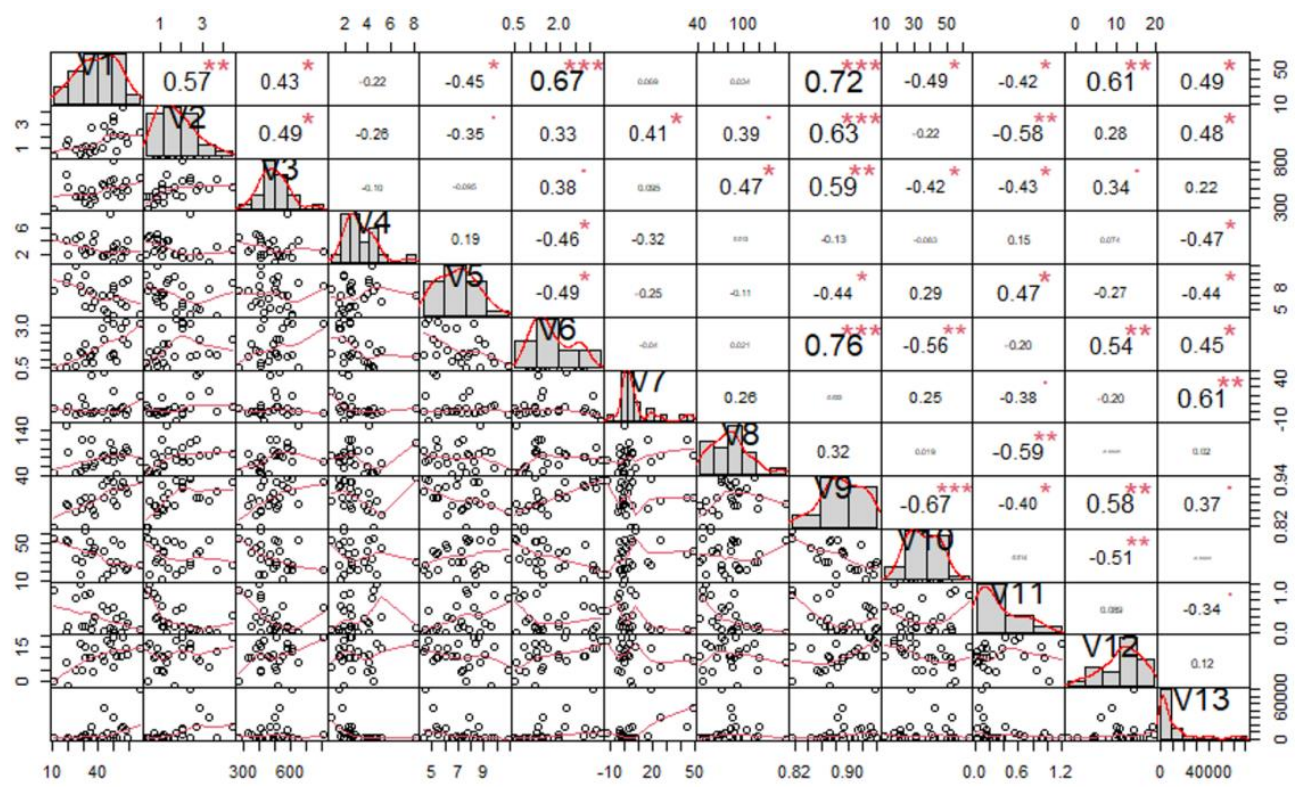

Figure 1. Correlation matrix

Source: Authors' results. $*$ indicates significance at 0.10 level, ${ }^{* *}$ at 0.05 , and $* * *$ at 0.01 .

HDI is seen strongly correlated with Recycling rate of municipal waste (V1), Resource productivity and domestic material consumption (V2), Generation of municipal waste per capita (V3) as well as R\&D expenditures (V6) in Figure 1. The strong connection between circular economy (CE) and HDI is justified as follows. $\mathrm{CE}$ is an economic system having the purpose of reducing waste and recycling it and the continual use of resources. This process is circular, has a regenerative approach and contrasts with linear economy, meant to produce goods with a finite life, using finite resources. The concept of CE is closer to the sustainable development than the traditional linear system. CE models consist of industry and policy activities of recycling, remanufacturing, reusing and waste management. CE concerns environmental issues such as resource depletion, waste management, environmental sustainability. The connection between $\mathrm{CE}$ and HDI refers to measures on poverty reductions and the sustainable use of resources and nature (Schröder et al., 2020). Neumayer (2012) emphasizes the multi-dimensionality of HDI: development, education and health together with freedom of choice. Also, Neumayer $(2010 ; 2012)$ associates human development with sustainability in its highest level (strong sustainability) and its lowest level (weak sustainability). In other words, human development can be measured by sustainable development in its forms: weak and strong sustainability. 
Eigenvalues, individual variability and cumulative variability

\begin{tabular}{|l|c|c|c|}
\hline & Eigenvalue & Variance (\%) & Cum. variance (\%) \\
\hline Dim.1 & 5.06768219 & $\mathbf{3 8 . 9 8 2 1 7 0 7}$ & 38.98217 \\
\hline Dim. 2 & 2.41740707 & $\mathbf{1 8 . 5 9 5 4 3 9 0}$ & 57.57761 \\
\hline Dim. 3 & 1.64174600 & $\mathbf{1 2 . 6 2 8 8 1 5 4}$ & $\mathbf{7 0 . 2 0 6 4 3}$ \\
\hline Dim. 4 & 0.89170279 & 6.8592522 & 77.06568 \\
\hline Dim. 5 & 0.74700226 & 5.7461712 & 82.81185 \\
\hline Dim. 6 & 0.53082938 & 4.0833029 & 86.89515 \\
\hline Dim. 7 & 0.48924761 & 3.7634432 & 90.65859 \\
\hline Dim. 8 & 0.39585181 & 3.0450139 & 93.70361 \\
\hline Dim. 9 & 0.30647087 & 2.3574682 & 96.06108 \\
\hline Dim.10 & 0.24270980 & 1.8669984 & 97.92808 \\
\hline Dim.11 & 0.13553319 & 1.0425630 & 98.97064 \\
\hline Dim.12 & 0.06952071 & 0.5347747 & 99.50541 \\
\hline Dim.13 & 0.06429632 & 0.4945871 & 100.00000 \\
\hline
\end{tabular}

Source: Authors' results.

In Table 1 we compute the eigenvalue retained by each principal component (PC). According to Kaiser principle, we retain the first three PCs, corresponding to the first three eigenvalues greater than 1 . Table 1 also contains the proportion of variance or information retained by each PC and the cumulative variance.

The third column of Table 1 contains the proportion of variation explained by each eigenvalue and the last column contains the cumulative percentage. In our analysis, the first three PCs explain $70.06 \%$ of the total variation. In Figure 2, the screeplot determines the numbers of PCs retained at the point where the remaining eigenvalues are small and comparable (Peres-Neto at al., 2005).

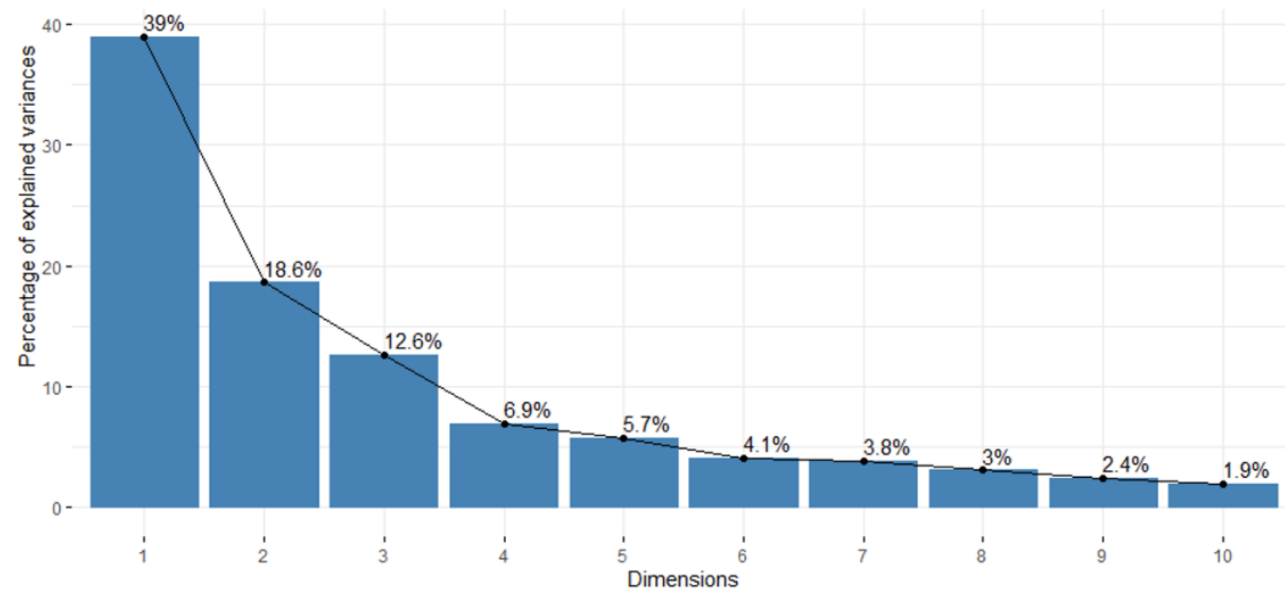

Figure 2. Scree plot of variance explained by principal components

Source: Authors' results.

Next, we derive conclusions on the correlations between the variables and the PCs. These correlations are known as the coordinates of the variables on the PCs. We refer to the quality of variables' representation on the factor map and their contribution to the PCs (Kassambara, 2017). Cos2 (square cosine) gives the quality of variable representation on factor map. The square cosines of variables on the first 5 PCs are 
represented in Figure 3. The first dimension is strongly dominated by Recycling rate of municipal waste (V1) and HDI (V9). The second dimension is determined by Annual change renewables. (V7).

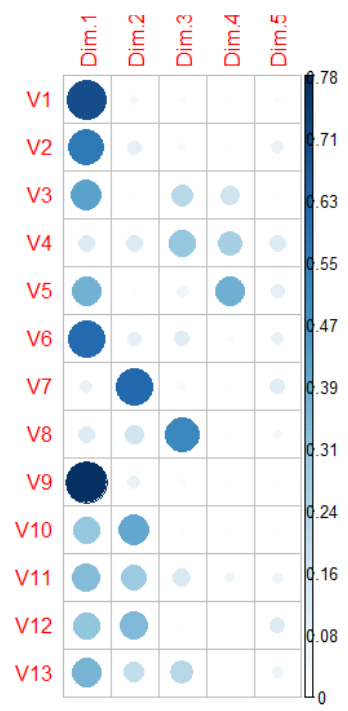

Figure 3. The $\cos 2$ of variables on the first 5 PCs

Source: Authors' results.

The correlations of variables seen in Figure 4, together with countries, show the relationships between all 13 variables. Positively correlated variables are grouped together. Negatively correlated variables are placed in the opposed quadrants. All variables are well represented on the factor map, since they are all far away from the origin. A good representation of the variables on the PCs is indicated by high cos 2 values. This also indicates that the variables with high values of $\cos 2$ are situated close to the circumference of the correlation circle. Smaller values of $\cos 2$ belong to variables closer to the center of the circle. In figure 4, variables with low values of $\cos 2$ are colored in white: Generation of municipal waste per capita (V3) and Environmental tax revenues (V5). Variables with middle values of $\cos 2$ are colored in blue: GDP per capita (V4) and Greenhouse gas emissions (V8). The remaining variables have high values of cos2 and are colored in red.

The initial data is represented in the biplot (Figure 4), which summarizes the determinants of the first two dimensions. Countries like Italy, Spain, France, Germany, Luxembourg, Netherlands, Austria, Denmark, Finland, Sweden, Slovenia, and Ireland have as strong determinants: Recycling rate of municipal waste (V1), Resource productivity and domestic material consumption (V2), Generation of municipal waste per capita (V3), (HDI) (V9), Adjusted net savings including emissions damage (V12) and National expenditure on environmental protection (V13). On the opposite pole are Romania, Bulgaria, Poland, Estonia, Hungary, Czech Republic, Lithuania, Slovakia, Cyprus, Lithuania. 


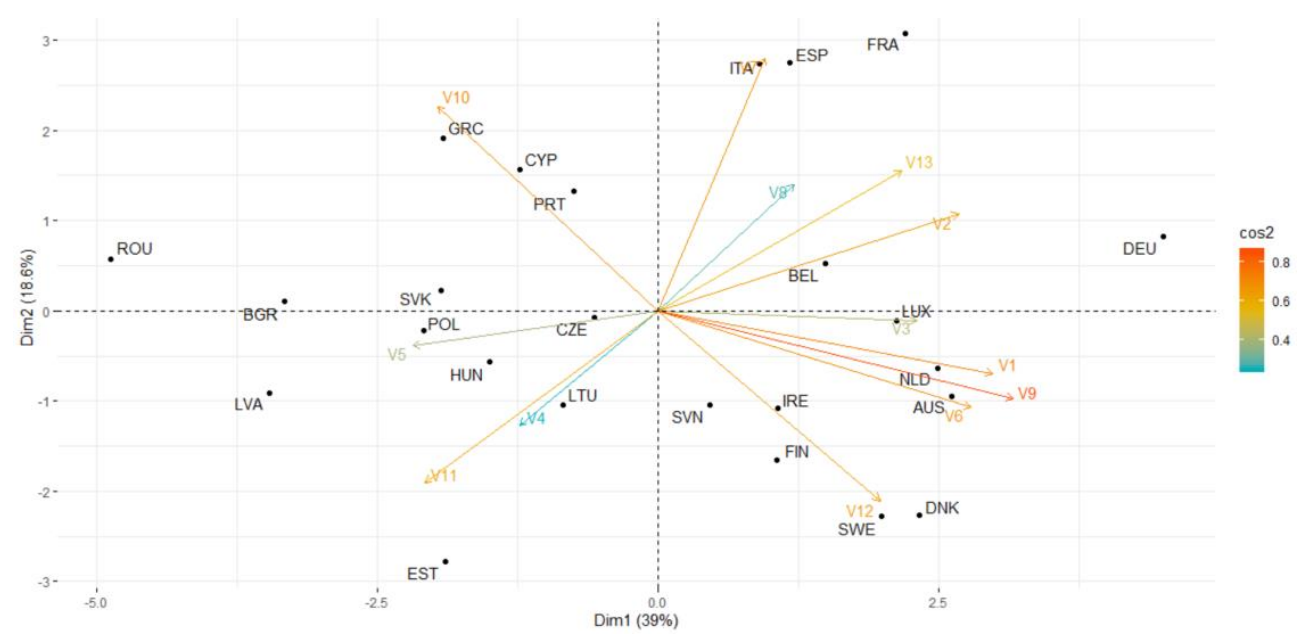

Figure 4. PCA biplot with countries and variables

Source: Authors' results.

However, we will retain the first 3 PCs with the component matrix seen in Table 2; this means that $70.06 \%$ of the information existing in the original data is retained by these 3 PCs (cf. Figure 2).

Table 2

Rotated component matrix after VARIMAX rotation

\begin{tabular}{|l|c|c|c|}
\hline & PC1 & PC2 & PC3 \\
\hline V1 & $\mathbf{0 . 7 5 0}$ & 0.386 & 0.210 \\
\hline V2 & 0.334 & 0.419 & $\mathbf{0 . 6 2 8}$ \\
\hline V3 & 0.468 & -0.016 & $\mathbf{0 . 6 4 1}$ \\
\hline V4 & -0.041 & $\mathbf{- 0 . 7 3 5}$ & 0.075 \\
\hline V5 & -0.386 & $\mathbf{- 0 . 5 1 0}$ & -0.173 \\
\hline V6 & $\mathbf{0 . 7 9 3}$ & 0.422 & -0.001 \\
\hline V7 & -0.329 & $\mathbf{0 . 6 8 0}$ & 0.373 \\
\hline V8 & -0.056 & -0.090 & $\mathbf{0 . 8 7 3}$ \\
\hline V9 & $\mathbf{0 . 8 2 5}$ & 0.172 & 0.412 \\
\hline V10 & $\mathbf{- 0 . 8 2 7}$ & 0.156 & -0.039 \\
\hline V11 & -0.043 & -0.340 & $\mathbf{- 0 . 7 9 8}$ \\
\hline V12 & $\mathbf{0 . 8 0 7}$ & -0.050 & -0.024 \\
\hline V13 & 0.174 & $\mathbf{0 . 8 5 6}$ & 0.143 \\
\hline
\end{tabular}

Source: Authors' results.

From Table 2, the first 3 PCs can be interpreted according to the magnitude and the direction of the loading factors. Only loadings in absolute value greater than 0.5 are considered. The main determinants of PC1 are: Recycling rate of municipal waste (V1) with the magnitude 0.75 , Greenhouse gas emissions (0.793), HDI (V9) (0.825), Adjusted net savings including emissions damage (V12) (0.807). Pollution Index (V10) has a negative impact on PC1 (-0.827). So, PC1 measures the environmental damage due to waste generation. PC2 is positively dominated by Annual change in renewables (V7) (0.680) and National expenditure on environmental protection (V13) (0.856) and negatively by GDP growth (V4) (-0.735), Environmental tax revenues (V5) (-0.510). PC3 is positively dominated by Resource productivity and domestic material consumption (V2) (0.628), Generation of municipal waste per capita (V3) (0.641) and 
Greenhouse gas emissions (V8) (0.873), and negatively dominated by Total natural resources rents (V11) (0.798). Based on Table 2, we can formulate indices for the three PCs:

- $\quad \mathrm{PC} 1=0.75 * \mathrm{~V} 1+0.793 * \mathrm{~V} 6+0.825 * \mathrm{~V} 9-0.827 * \mathrm{~V} 10+0.807 * \mathrm{~V} 12$

- $\quad$ PC2 $=-0.735 * \mathrm{~V} 4-0.51 * \mathrm{~V} 5+0.68 * \mathrm{~V} 7+0.856 * \mathrm{~V} 13$

- $\quad$ PC $3=0.628 * \mathrm{~V} 2+0.641 * \mathrm{~V} 3+0.873 * \mathrm{~V} 8-0.798 * \mathrm{~V} 11$

As we retained three PCs, we can further compute the weights for each PC taking the ratio of the total variance explained by each PC (i.e., $38.982 \%, 18.595 \%$ and $12.629 \%$ for PC1, PC2 and PC3, respectively as seen in Table 1) and the total cumulative variance explained by the retained three PCs (i.e., $70.206 \%$ in Table 1). For comparable purposes, multiplying PC1 by 0.555 (38.982/70.206), PC2 by 0.265 and PC3 by 0.180 and summing them up, gives us the Circular Economy Index:

- $\quad \mathrm{CEI}=0.416 * \mathrm{~V} 1+0.113 * \mathrm{~V} 2+0.115^{*} \mathrm{~V} 3-0.195 * \mathrm{~V} 4-0.135^{*} \mathrm{~V} 5+0.440 * \mathrm{~V} 6+0.180 * \mathrm{~V} 7+$ $0.157 * \mathrm{~V} 8+0.458 * \mathrm{~V} 9-0.459 * \mathrm{~V} 10-0.144 * \mathrm{~V} 11+0.448 * \mathrm{~V} 12+0.227 * \mathrm{~V} 13$

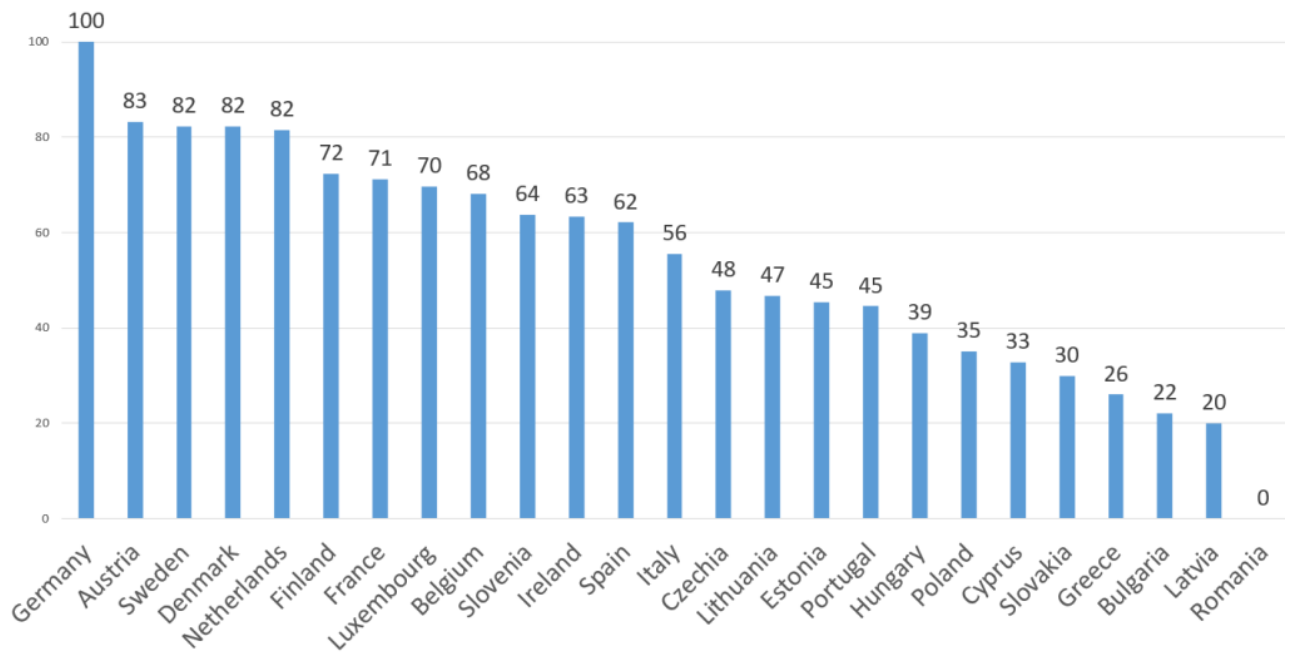

Figure 5. Circular Economy Index, CEI

Source: Authors' results.

Using the standardized country data and scaling the values between 0 and 100 (by Min-Max normalization), we obtain CEI for each country shown in Figure 5. The highest values are seen for Germany, Austria, Sweden, Denmark, and Netherlands, in this order, Germany having CEI=100; the lowest performance is seen in Poland, Cyprus, Slovakia, Greece, Bulgaria, Latvia, and lastly Romania, which obtains $\mathrm{CEI}=0$

Variables contributing most to the retained first three PCs were HDI (V9), R\&D expenditure as a share of GDP (V6), National expenditure on environmental protection (V13), Greenhouse gas emissions (V8), Recycling rate of municipal waste (V1), Total natural resources' rents as a share of GDP (V11), Annual change increase of renewables (V7), and the Pollution Index (V10), in this order.

For possible future research, the use of longer time-series data may be valuable. Larger sample of countries would also offer opportunities to more generalizable outcomes. This is, for instance, because the European Union members, even showing division with regards to circular economy, represent rather well developed and sustainable market economies, while the set of more diverse countries could reveal more 
fundamental relations of national strategies towards circular economy and the obtained benefits and costs. Generalizability may be limited also for the country sample restricted to relatively well-developed market economies of European Union, while large part of world countries do not operate under similar economic and political environments

\section{CONCLUSION}

The current state of circular economy of the $25 \mathrm{EU}$ member states was under investigation. The circular economy has been better utilized by Western European countries such as Germany, Austria, or Netherlands as well as Nordic countries than the Eastern and Southern areas of the European Union such as Greece, Latvia, Bulgaria, or Romania. High pollution index was related to low circular economy index as shown specifically by Greece, Cyprus, and Portugal, while greenhouse gas emissions were related and compensated by higher expenditures to environmental protection; increase in renewables seemed interestingly to be related to countries such as Italy, Spain, and France. The most developed areas as measured by HDI were seen to invest most also into environmental protection, recycling, renewables, and R\&D. For example, HDI, recycling rate and $\mathrm{R} \& \mathrm{D}$ expenditures seemed related to countries like Austria and Netherlands. These countries had identified options to develop their circular economy and acted on it to gain in their long-term sustainable development.

\section{REFERENCES}

Androniceanu, A.-M., Kinnunen, J., Georgescu, I., \& Androniceanu, A. (2020). A multidimensional approach to competitiveness, innovation and well-being in the EU using canonical correlation analysis. Journal of Competitiveness, 12(4), 5-21. doi: 10.7441/joc.2020.04.01

Bagirova, A., \& Notman, O. (2020). The well-being of residents in an urban environment: the case of a Russian megapolis. Administratie si Management Public, 35, 124-138. doi: 10.24818/amp/2020.35-08

Banaité, D., (2016). Towards a circular economy: Analysis of indicators in the context of sustainable development. Retrieved January 4, 2021, from http://stics.mruni.eu/wp-content/uploads/2016/07/STICS 20164142 150.pdf

Belas, J., Amoah, J., Petráková, Z., Kliuchnikava, Y., \& Bilan, Y. (2020). Selected Factors of SMEs Management in the Service Sector. Journal of Tourism and Services, 21(11), 129-146. doi: https://dx.doi.org/10.29036/jots.v11i21.215

Bilan Y., Mishchuk, H., Roshchyk, I., \& Kmecova I. (2020). Analysis of intellectual potential and its impact on the social and economic development of European countries. Journal of Competitiveness, 1, 22-38. https://doi.org/10.7441/joc.2020.01.02

Bilas, V. (2020). FDI and economic growth in EU13 countries: Cointegration and causality tests. Journal of Competitiveness, 12(3), 47-63. Doi: https://doi.org/10.7441/joc.2020.03.03

Boulding, K. (1966). The economics of the coming spaceship earth. Resources for the Future. Retrieved January 11, 2021, http://arachnid.biosci.utexas.edu/ courses/THOC/Readings/BouldingSpace shipEarth.pdf

Connolly-Barker, M., Kliestik, T., Suler, P., \& Zvarikova, K. (2020). Real-time decision-making in the information technology-driven economy: planning, managing, and operating smart sustainable cities. Geopolitics, History, and International Relations. 12(1), 73-79. doi:10.22381/GHIR12120206

Dvorský, J., Petráková, Z., Khan, K.A., Formánek, I., \& Mikoláš, Z. (2020). Selected aspects of strategic management in the service sector. Journal of Tourism and Services, 20(11), 109-123. doi: https://doi.org/10.29036/jots.v11i20.146.

Ellen MacArthur Foundation. (2013). Towards the Circular Economy. Economic and Business Rationale for an Accelerated Transition. Retrieved December 14, 2020, from https://www.ellenmacarthurfoundation.org/assets/downloads/publications/Ellen-MacArthur-FoundationTowards-the-Circular-Economy-vol.1.pdf 
Esposito, M., Tse, T., \& Soufani, K. (2015). Is the circular economy a new fast-expanding market?. Thunderbird International Business Review, 59(1), 9-14. Doi: 10.1002/tie.21764.

Gavurova, B., Kubak, M., \& Mikeska, M. (2020). The efficiency of public procurement in the health sector - the platform on sustainable public finances. Administratie si Management Public, 35, 21-39. doi:10.24818/amp/2020.35-02

Geissdoerfer, M., Savaget, P., Bocken, N., \& Hultink, E. (2017). The circular economy - a new sustainability paradigm?. Journal of Cleaner Production, 143, 757-768.

Geng, Y., Fu, J., Sarkis, J., \& Xue, B. (2012). Towards a national circular economy indicator system in China: an evaluation and critical analysis. Journal of Cleaner Production, 23, 216-224. doi:https://doi.org/10.1016/j.jclepro.2011.07.005.

Geng, Y., Sarkis, J., Ulgiati, S., \& Zhang, P. (2013). Measuring China's circular economy. Science, 339(1627), $1526-1527$. doi: $10.1126 /$ science.1227059.

Habanik, J., Martosova, A., \& Letkova, N. (2020). The impact of managerial decision-making on employee motivation in manufacturing companies. Journal of Competitiveness, 12(2), 38-50. doi:https://doi.org/10.7441/joc.2020.02.03

Haseeb, M., Kot, S., Iqbal Hussain, H., \& Kamarudin, F. (2021), The natural resources curse-economic growth hypotheses: Quantile-on-Quantile evidence from top Asian economies. Journal of Cleaner Production, 279, art. no. 123596. doi: 10.1016/j.jclepro.2020.123596

Hodgkins, S. (2020). Big data-driven decision-making processes for environmentally sustainable urban development: the Design, planning, and operation of smart city infrastructure. Geopolitics, History, and International Relations, 12(1), 87-93. doi:10.22381/GHIR12120208

Ionescu, L. (2020). The economics of the carbon tax: environmental performance, sustainable energy, and green financial behavior. Geopolitics, History, and International Relations, 12(1), 101-107. doi:10.22381/GHIR121202010

Joliffe, I. T. (2002). Principal component analysis. Springer. Second edition.

Kassambara, A. (2017). Practical guide to principal component methods in R, STHDA.

Mazzoni, F. (2020). Circular economy and eco-innovation in Italian industrial clusters. Best practices from Prato textile cluster. Insights into Regional Development, 2(3), 661-676. https://doi.org/10.9770/IRD.2020.2.3(4)

Mendy, D., \& Widodo, T. (2018). Do education levels matter on Indonesian economic growth?. Economics and Sociology, 11(3), 133-146. doi:10.14254/2071- 789X.2018/11-3/8

Khan, K.A., Dankiewicz, R., Kliuchnikava, Y., \& Oláh, J. (2020). How do entrepreneurs feel bankruptcy?. International Journal of Entrepreneurial Knowledge, 8(1), 89-101. doi: 10.37335/ijek.v8i1.103

Kinnunen, J., Androniceanu, A., \& Georgescu, I. (2019). The role of economic and political features in classification of countries-in-transition by human development index. Informatica Economica, 23(4), 26-40. doi:10.12948/issn14531305/23.4.2019.03

Kosach, I., Duka, A., Starchenko, G., Myhaylovska, O., \& Zhavoronok, A. (2020). Socioeconomic viability of public management in the context of European integration processes. Administratie si Management Public, 35, $139-152$. doi: 10.24818/amp/2020.35-09

Krisnaresanti, A., Julialevi, K.O., Naufalin, L.R., \& Dinanti, A. (2020). Analysis of entrepreneurship education in creating new entrepreneurs. International Journal of Entrepreneurial Knowledge, 8(2), 67-76. doi:https://doi.org/10.37335/ijek.v8i2.112

Moraga, G., Huysveld, S., Mathieux, F., Blengini, G., Alaerts, L., Van Acker, K., de Meester, S., \& Dewulf, J. (2019). Circular economy indicators: What do they measure?. Resources, Conservation and Recycling, 146, 452-461.

Morgan, C. (2020). Can smart cities be environmentally sustainable? urban big data analytics and the citizen-driven internet of things. Geopolitics, History, and International Relations, 12(1), 80-86. doi:10.22381/GHIR12120207

Mura, L., Gontkovicova, B., Dulova Spisakova, E., \& Hajduova, Z. (2019). Position of employee benefits in remuneration structure. Transformations in Business \& Economics, 18, 2(47), 156-173.

Nekmahmud, M., Rahman, S., Sobhani, F.A., Olejniczak-Szuster, K., \& Fekete-Farkas, M. (2020). A systematic literature review on development of green supply chain management. Polish Journal of Management Studies, 22(1), 351-370. doi: 10.17512/pjms.2020.22.1.23 
Nelson, A., \& Neguriță, O. (2020). Big data-driven smart cities: internet of things devices and environmentally sustainable urban development. Geopolitics, History, and International Relations, 12(2), 37-43. doi:10.22381/GH IR12220205

Neumayer, E. (2012). Human development and sustainability. Journal of Human Development and Capabilities, 13(4), 561579. doi: $10.1080 / 19452829.2012 .693067$

Neumayer, E. (2010). Weak versus strong sustainability. Exploring the limits of two opposing paradigms. Edward Elgar. Cheltenham, $3^{\text {rd }}$ edition.

Nikanorova, M., \& Stankevičienè, J. (2020). Development of environmental pillar in the context of circular economy assessment: Baltic Sea Region case. Entrepreneurship and Sustainability Issues, 8(1), 1209-1223. doi:http://doi.org/10.9770/jesi.2020.8.1(81)

Pearce, D.W., \& Turner, R.K. (1990). Economics of Natural Resources and the Environment. Baltimore: The Johns University Press.

Peres-Neto, P.R., Jackson, D.A., \& Somers, K.M. (2005). How many principal components? Stopping rules for determining the number of non-trivial axes revisited. Computational Statistics \& Data Analysis, 49(4), 974-997. https://doi.org/10.1016/j.csda.2004.06.015

Př́vara, A., \& Kiner, A. (2020). Immigrant employment in the Slovak hospitality industry: profiles, experience, and education. Journal of Tourism and Services, 20(11), 167-182. doi: https>//dx.doi.org/10.29036/jots.v11i21.223

Rozsa, Z., Formánek, I., \& Maňák, R. (2019). Determining the factors of the employees' intention to stay or leave in the Slovak's SMEs. International Journal of Entrepreneurial Knowledge, 7(2), 63-72. https://doi.org/10.37335/ijek.v7i2.94

Schröder, P., Lemille, A., \& Desmond, P. (2020). Making the circular economy work for human development, Resources, Conservation \& Recycling 156, 104684, https://doi.org/10.1016/j.resconrec.2020.104686

Shpak, N., Melnyk, O., Horbal, N., Ruda, M., \& Sroka, W. (in press, 2021). Assessing implementation of circular economy in the EU countries. Forum Scientiae Oeconomia.

Shpak, N., Kuzmin, O., Melnyk, O., Ruda, M., \& Sroka, W. (2020). Implementation of circular economy in Ukraine: context of European integration, Resources, 9, 96. doi: 10.3390/resources 9080096

Stankevičius A, Novikovas A., Bakaveckas A., \& Petryshyn O. (2020). EU waste regulation in the context of the circular economy: peculiarities of interaction. Entrepreneurship and Sustainability Issues, 8(2), 533-545. http://doi.org/10.9770/jesi.2020.8.2(32)

Steffen, W., Richardson, K., Rockström, J., Cornell, S.E., Fetzer, I., Bennett, E.M. et al., (2015). Planetary boundaries: Guiding human development on a changing planet. Science, 347(6223). doi: 10.1126/science.1259855.

Vlacseková, D., \& Mura, L. (2017). Effect of motivational tools on employee satisfaction in small and medium enterprises. Oeconomia Copernicana, 8 (1), 111-130.

Zielińska, A. (2019). Comparative analysis of circular economy implementation in Poland and other European Union countries. Journal of International Studies, 12(4), 337-347. doi:10.14254/2071-8330.2019/12-4/22

Walker, A., Rowland, Z., Frajtova Michalikova, K., \& Svabova, L. (2020). Urban mobility technologies, algorithmdriven sensing devices, and machine learning-based ethical judgments in a connected vehicle environment. Contemporary Readings in Law and Social Justice, 12(2), 34-42. doi:10.22381/CRLSJ12220204 